\begin{tabular}{ll}
\hline & Jurnal Sains Materi Indonesia \\
Homepage: http://jusami.batan.go.id & $\begin{array}{l}\text { Akreditasi LIPI } \\
\text { No.: 602/AU3/P2MI-LIPI/03/2015 } \\
\text { Tanggal 15 April 2015 } \\
\text { ISSN : 1411-1098 }\end{array}$ \\
\hline
\end{tabular}

\title{
KARAKTERISASI SIFAT TERMAL DAN OPTIK POLYDIMETHYLSILOXANE SEBAGAI LENSA INVERS
}

\author{
Yenny Meliana ${ }^{1}$, Andinnie Juniarsih ${ }^{2}$ dan Juvitha Anggraini ${ }^{2}$ \\ ${ }^{1}$ Pusat Penelitian Kimia - LIPI \\ Kawasan Puspiptek, Serpong 15314, Tangerang Selatan \\ ${ }^{2}$ Teknik Metalurgi Universitas Sultan Ageng Tirtayasa \\ Cilegon 42118 \\ E-mail: yenn001@lipi.go.id
}

Diterima: 6 Februari 2017 Diperbaiki: 28 April $2017 \quad$ Disetujui: 4 Mei 2017

\begin{abstract}
ABSTRAK
KARAKTERISASI SIFAT TERMAL DAN OPTIK POLYDIMETHYLSILOXANE SEBAGAI LENSA INVERS. Polydimethylsiloxane (PDMS) adalah karet silikon yang stabil secara fisik dan kimia dan telah tersedia komersial. PDMS merupakan material polimer dengan rentang indeks bias 1,47-1,55 dan mempunyai karakter transparansi yang tinggi mencapai $95 \%$ sehingga bahan ini baik digunakan sebagai alat optik sederhana berupa lensa invers. Penelitian ini bertujuan untuk membuat lensa invers dari polimer PDMS serta mengetahui sifat optik dan termalnya.Tahapan penelitian lensa invers meliputi: pencampuran antara base PDMS dengan curing agent PDMS dengan perbandingan $10: 1$, kemudian dilakukan proses penetesan diatas slide kaca lalu dibalikkan (invers) dengan variasi jumlah tetesan 2,3 dan 4 drop dan terakhir dilakukan proses curing dengan variasi suhu curing $70{ }^{\circ} \mathrm{C}, 80^{\circ} \mathrm{C}$, dan $90^{\circ} \mathrm{C}$. Karakterisasi bahan meliputi analisis morfologi lensa menggunakan SEM/EDX, intensitas cahaya menggunakan luxmeter serta analisis nilai transtition glass (Tg) menggunakan TGA/DTA. Hasil karakterisasi analisis luxmeter menunjukkan semakin rendah suhu curing semakin tinggi intensitas cahaya yang dapat menembus lensa. Foto SEM memeperlihatkan adanya gelembung pada lensa. Semakin besar volume lensa maka semakin sedikit gelembung pada lensa. Hasil analisis menggunakan TGA memperlihatkan untuk rentang suhu pemanasan antara $70{ }^{\circ} \mathrm{C}$ hingga $90^{\circ} \mathrm{C}$ nilai suhu degradasi (Td) lensa invers tidak berpengaruh signifikan. Hasil penelitian ini menunjukkan bahwa lensa yang baik adalah pada variasi 4 tetes dan suhu curing $70{ }^{\circ} \mathrm{C}$ dengan nilai intensitas 177 lux dan nilai Td sebesar $301,5^{\circ} \mathrm{C}$
\end{abstract}

Kata kunci: Polydimethylsiloxane, Suhu, Tetesan, Intensitas cahaya, Termal

\begin{abstract}
CHARACTERIZATION THERMAL AND OPTICAL PROPERTIES OF POLYDIMETHYL SILOXANE AS LENS INVERSE. Polydimethylsiloxane (PDMS) is stable silicone rubber by physical and chemical. This material available by commercially.PDMS is a polymer material has a refractive index of 1.47 to 1.55 and high transparency till $95 \%$ that it best used as simple optical instruments such as an inverse lens. The aims this study is to create the inverse lens of PDMS and investigated the optical and thermal properties this polymer.Step researches are mixing, dripping, invers, and curing. Mixing is done by PDMS base with PDMS curing agent in ratio 10:1. Then dripping on a glass slide and then inverted with variations droplets is 2,3 , and 4 drops. Curing has variations temperature is 70,80 , and $90{ }^{\circ} \mathrm{C}$. Characterizations are use SEM, lux meter, and TGA. The result of lux meter analysis is the lower temperature can be higher light intensity. SEM showed bubbles on the lens which the more high volume of lens can be more less bubbles on the lens. TGA analysis showed there is no significant change for value of degradation (Td) for the curing temperature in the range $70^{\circ} \mathrm{C}$ to $90{ }^{\circ} \mathrm{C}$. The best results are used with a variety of 4 drops at temperature of $70{ }^{\circ} \mathrm{C}$ with value of intensity at 177 lux and value of $\mathrm{Td}$ at $301,5^{\circ} \mathrm{C}$.
\end{abstract}

Keywords: Polydimethylsiloxane, Suhue, Dripping, Light intensity, Thermal 


\section{PENDAHULUAN}

Polimer adalah rantai berulang dari atom yang panjang terbentuk dari pengikat yang berupa molekul identik yang disebut monomer [1]. Polimer digunakan sebagai karet, plastik, botol dan lain-lain.Seiring dengan perkembang waktu, polimer dapat digunakan sebagai bahan dasar pembuatan lensa. Lensa yang terbuat dari polimer ini memiliki keunggulan dimana mampu melakukan perbesaran 60 kali hingga 100 kali. PDMS dapat digunakan sebagai lensa optik yang jernih, umumnya bersifat inert, tidak beracun dan tidak mudah terbakar. Dimethicone adalah nama lain, merupakan salah satu dari beberapa jenis minyak silikon (polymerised siloxane) [2]. Saat ini lensa yang terbuat dari bahan polimer memiliki kekurangan yaitu tidak dapat dibuat dengan ukuran lebih dari 1 inchi, mudah meleleh dan mudah terjadi degradasi apabila digunakan pada suhu tinggi $\left(>100^{\circ} \mathrm{C}\right)$ [3]. Lee dkk telah melakukan pembuatan lensa polydimethylsiloxane (siliKon) dengan menggunakan substrat berbentuk curve yang mempunyai sifat yang bagus [3].

Dari berbagai material polimer, silikon mempunyai kelebihan karena sifat elastisitasnya yang tinggi dan tahan terhadap degradasi lingkungan [4]. Silikon berbasis elastomer PDMS merupakan salah satu material teknik polimer yang popular sebab sifat-sifatnya seperti biokompatibilitas tinggi, fleksibel dan stabil secara mekanik, proses pembuatannya murah, dan transparansi pada spektrum $U V, V I S$, dan NIR [5]. PDMS merupakan optik transparan (UV cutoff, $240 \mathrm{~nm})$ dan memiliki konduktivitas termal $0.2 \mathrm{~W} / \mathrm{m} \mathrm{K}$ [6]. Selain itu, untuk membentuk membran komposit, PDMS larut dalam berbagai pelarut organik [7], juga memliki permukaan superhidrofobik yang transparan $[8,9]$.

Berdasarkan penelitian yang pernah dilakukan oleh Lee dkk, polimer jenis polydimethylsiloxane dapat digunakan sebagai lensa karena mempunyai indeks bias sebesar 1,47 hingga 1,55 [2]. Hal inilah yang membuat para peneliti menggunakan bahan polydimethylsiloxane sebagai lensa yang dapat digunakan sebagai alat optik sederhana. Keunggulan polydimethylsiloxane sebagai alat optik yang telah diteliti oleh para peneliti sebelumnya adalah memiliki indeks bias pada rentangn sebesar 1,47 hingga 1,55 dan memiliki tingkat transparan lebih dari $95 \%$.

Selain itu, PDMS memiliki crosslinking yang berguna untuk meningkatkan ketahanan dan kekuatan material.Crosslinking dapat meningkatkan kekuatan dikarenakan terdapat rantai polimer yang membentuk ikatan dua rantai yang membentuk ikatan silang yang berulang-ulang [10]. Karakterisasi termal dibutuhkan agar lensa tidak rusak atau meleleh pada saat diaplikasikan ke kamera handphone dan indeks bias sebesar 1,47 [2]. Karakterisasi termal diukur berdasarkan reaksi dekomposisi ini. Stabilitas termal berhubungan erat dengan energi ikatan antara atom-atom dalam polimer, energi ikatan yang tinggi akan menghasilkan stabilitas thermal yang lebih tinggi [11]. Sehingga perlu adanya penelitian lanjutan untuk mengetahui sifat thermal dari polydimethylsiloxane. Pada penelitian ini di harapkan dapat di ketahui karakter termal dan sifat optikdari lensa invers polydimethylsiloxane

\section{METODE PERCOBAAN}

\section{Bahan dan Alat}

Bahan yang digunakan dalam penelitian ini adalah 184 elastomer kit dow corning yang terdiri dari Polydimethylsiloxane (PDMS)dan silicone elastomer curing agent dari Dow Corning.

Alat karakterisasi yang digunakan adalah Scanning Electron Microscope (SEM) JEOL JSM-6390A untuk analisis morfologi lensa invers.Thermogravimetric Analysis (TGA) Linseis untuk analisis degradasi pada polimer, dan Lux meter IEEE untuk analisis intensitas cahaya.

\section{Cara Kerja}

Polydimethylsiloxane (PDMS) dicampurkan dengan curing agent dengan perbandingan 10 : 1. PDMS diaduk dengan curing agent hingga tercampur rata dan didiamkan agar residu gelembung berkurang. Proses penetesan pertama dilakukan menggunakan suntikan ke atas slide kaca dengan pada variasi suhu oven $70{ }^{\circ} \mathrm{C}$, $80{ }^{\circ} \mathrm{C}$, dan $90{ }^{\circ} \mathrm{C}$ selama 15 menit pertetesan. Penetesan berikutnya dengan cara invers pada variasi jumlah tetesan $0,032 \mathrm{~mL}$ (2 tetes), 0,048 $\mathrm{mL}$ (3 tetes) dan $0,064 \mathrm{~mL}$ (4 tetes).

\section{HASIL DAN PEMBAHASAN}

Sampel lensa invers yang didapat dengan mencampurkan base PDMS dengan curing agent dengan perbandingan 10:1 sebanyak 2 tetes (volume pertetes sebanyak $0,016 \mathrm{~mL}$ ) pada suhu $70{ }^{\circ} \mathrm{C}$, dapat dilihat pada Gambar 1.

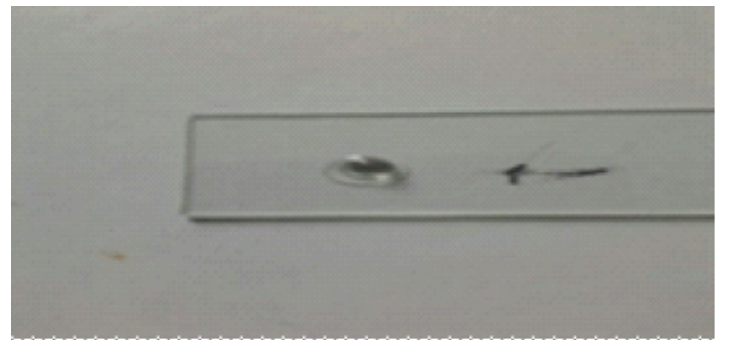

Gambar 1. Sampel lensa invers dari base PDMS dengan curing agent $(10: 1)$ sebanyak $0,032 \mathrm{~mL}$ pada suhu $70^{\circ} \mathrm{C}$.

Proses penetesan dilakukan diatas preparat kaca lalu membalikkannya hingga membentuk cembungan dengan variasi jumlah tetesan. 


\section{Pengamatan Intensitas Cahaya}

Hasil pengamatan intensitas cahaya lensa invers yang dimulai dari mixingdroplet,invers dan curing dengan variasi suhu yang berbeda. Variasi suhu yang di lakukan yaitu pada suhu $70{ }^{\circ} \mathrm{C}, 80^{\circ} \mathrm{C}$, dan $90^{\circ} \mathrm{C}$. Variasi jumlah tetesan yaitu $0,032 \mathrm{~mL}, 0,048 \mathrm{~mL}$, dan $0,064 \mathrm{~mL}$ yang dilakukan untuk mengetahui besar intensitas cahaya yang dapat menembus lensa. Hasil pengukuran intensitas cahaya lensa invers dengan variasi suhu curing dan jumlah tetesan yang dilakukan dengan menggunakan sember cahaya lampu pijar 12 volt, jarak antara sumber cahaya ke kaca (Rm) sepanjang $2 \mathrm{~cm}$, dan jarak antara medium ke lensa invers (Rl) $2 \mathrm{~cm}$. Seperti diperlihatkan pada Tabel 1 yang menunjukan besarnya intensitas cahaya yang dapat menembus lensa invers tersebut.

Tabel 1. Data hasil pengukuran intensitas cahaya.

\begin{tabular}{ccccc}
\hline Suhu $\left({ }^{\circ} \mathrm{C}\right)$ & $\begin{array}{c}\text { Jumlah } \\
\text { Tetesan }(\mathrm{ml})\end{array}$ & $\begin{array}{c}\text { Intensitas } \\
(\text { Lux })\end{array}$ & $\begin{array}{c}\mathrm{Rm} \\
(\mathrm{cm})\end{array}$ & $\begin{array}{c}\mathrm{R} 1 \\
(\mathrm{~cm})\end{array}$ \\
\hline \multirow{3}{*}{$70^{\circ} \mathrm{C}$} & 0,032 & 173 & 2 & 2 \\
& 0,048 & 175 & 2 & 2 \\
\hline \multirow{3}{*}{$80^{\circ} \mathrm{C}$} & 0,064 & 177 & 2 & 2 \\
\hline \multirow{2}{*}{$90^{\circ} \mathrm{C}$} & 0,032 & 160 & 2 & 2 \\
& 0,048 & 162 & 2 & 2 \\
& 0,064 & 170 & 2 & 2 \\
\hline
\end{tabular}

Pada Tabel 1 dapat dilihat bahwa semakin banyak jumlah tetesan maka semakin besar intensitas cahaya yang dapat ditembus oleh cahaya. Sedangkan semakin tinggi suhu maka intensitas yang didapatkan semakin kecil. Hal ini terjadi karenasemakin besar jumlah tetesan maka semakin cembung lensa yang terbentuk. Lensa cembung memiliki sifat dapat mengumpulkan cahaya (kovergen) sehingga nilai intensitas cahaya semakin besar [12]. Selain itu, suhu juga mempengaruhi intensitas cahaya,dimana semakin tinggi suhu curing semakin cepat terjadi cross linking yang menyebabkan banyak gelembung yang terperangkap pada lensa invers. Gelembung pada lensa dapat mengakibatkan pemantulan baur (difus) sehingga cahaya yang terbaur tersebut tidak fokus dan tidak terdeteksi pada lux meter [13].

Dari Gambar 2 pada grafik dijelaskan pada suhu $70{ }^{\circ} \mathrm{C}$ memiliki nilai intensitas cahaya yang besar yakni untuk sampel dengan jumlah tetesan $0,032 \mathrm{~mL}$ sebesar 173 lux, jumlah tetesan $0,048 \mathrm{~mL}$ sebesar 175 lux, dan jumlah tetesan 0,064 mL sebesar 177 lux. Hal ini disebabkan lensa pada suhu $70^{\circ} \mathrm{C}$ memiliki waktu proses terjadinya crosslinking lebih lambat sehingga gelembung udara yang terperangkap pada lensa dapat keluar terlebih dahulu. Gelembung udara menyebabkan cahaya yang datang akan dibaurkan karena adanya perbedaan kerapatan optik medium 1 dan medium 2. Hal ini yang terjadi pada lensa invers karena pada sampel lensa invers terdapat gelembung yang menyebabkan perbedaan kerapatan dengan bagian lensa invers yang terbuat dari PDMS dengan gelembung udara.

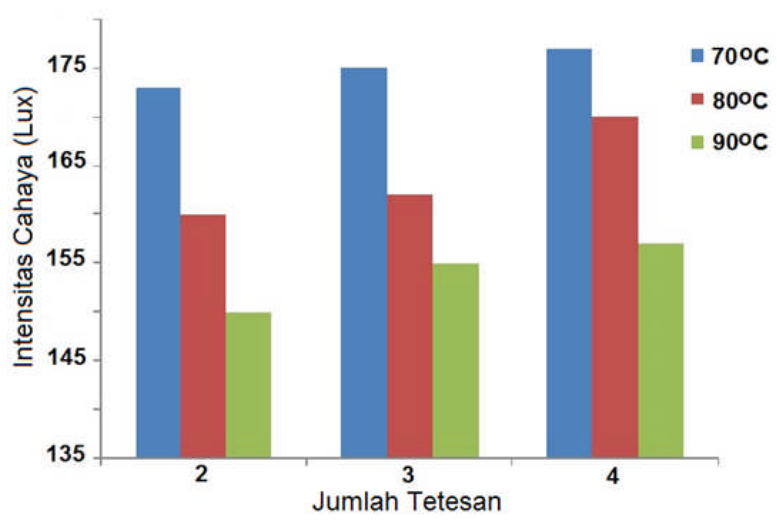

Gambar 1. Grafik hasil pengukuran intensitas cahaya

Gelembung pada lensa memiliki kerapatan optik yang berbeda mengakibatkan terjadi pembauran sehingga cahaya mengalami penyimpangan menjauhi garis normal. Sesuai dengan Hukum II Snellius (hukum II Pembiasan) yang berbunyi : Sinar datang dari medium kurang rapat menuju ke medium lebih rapat dibiaskan mendekati garis normal. Sebaliknya, sinar datang dari medium lebih rapat menuju ke medium kurang rapat dibiaskan menjauhi garis normal [13]. Sehingga pada lensa dengan variasi tetesan semakin banyak dan suhu semakin rendah nilai intensitas cahaya lebih besar karena gelembung pada lensa semakin sedikit.

Lensa dengan jumlah tetesan yang sedikit akan mengalami waktu curing yang lebih cepat. Oleh karena itu, lensa invers dengan jumlah tetesan sedikit lebih banyak gelembung udara terperangkap pada lensa yang menyebabkan pembauran cahaya. Pembauran cahaya menyebabkan cahaya tidak fokus ke lux meter sehingga nilai intensitasnya rendah karena terjadi perbedaan kerapatan dimana kerapatan $P D M S$ lebih rapat dibandingkan dengan udara [13].

Gambar 2 untuk suhu $90{ }^{\circ} \mathrm{C}$ terlihat memiliki intensitas cahaya yang paling kecil dimana jumlah tetesan 0,032 mL sebesar 150 lux, jumlah tetesan 0,048 $\mathrm{mL}$ sebesar 155 lux, dan jumlah tetesan $0,064 \mathrm{~mL}$ sebesar 157 lux. Dari hasil pengujian intesitas maka didapatkan nilai intensitas tertinggi ialah pada suhu $70^{\circ} \mathrm{C}$ dengan jumlah tetesan $0,064 \mathrm{~mL}$ yaitu sebesar 177 lux, sedangkan yang terkecil pada suhu $90{ }^{\circ} \mathrm{C}$ dengan jumlah tetesan $0,032 \mathrm{~mL}$ yaitu sebesar 50 lux. Hasil ini juga didukung dengan hasil dari analisis morfologi dengan menggunakan SEM.

\section{Analisis SEM}

Pengujian SEM dilakukan terhadap sampel yang mempunyai variasi suhu, yaitu; $70{ }^{\circ} \mathrm{C}, 80^{\circ} \mathrm{C}$, dan $90{ }^{\circ} \mathrm{C}$ serta variasi jumlah tetesan yaitu $0,032 \mathrm{~mL}, 0,048 \mathrm{~mL}$, dan $0,064 \mathrm{~mL}$. 
Pada Gambar 3 menunjukkan hasil SEM pada suhu $70{ }^{\circ} \mathrm{C}$ dengan variasi jumlah tetesan $0,032 \mathrm{~mL}, 0,048 \mathrm{~mL}$, dan $0,064 \mathrm{~mL}$. Pada gambar tersebut dapat dilihat bahwa jumlah tetesan $0,032 \mathrm{~mL}$ memiliki gelembung udara sedikit tetapi gelembung udara yang terbentuk cukup besar. Pada lensa invers dengan jumlah tetesan $0,048 \mathrm{~mL}$ tetes terdapat banyak gelembung udara yang terperangkap tetapi volume gelembung udaranya lebih kecil, sedangkan pada jumlah tetesan 0,064 mL ditemukan lamel dan gelembung udara yang banyak. Lamel terbentuk dari gelembung udara yang saling bergabung dan ingin bergerak keluar sehingga gabungan gelembung udara yang belum keluar berbentuk lamel pada hasil SEM.
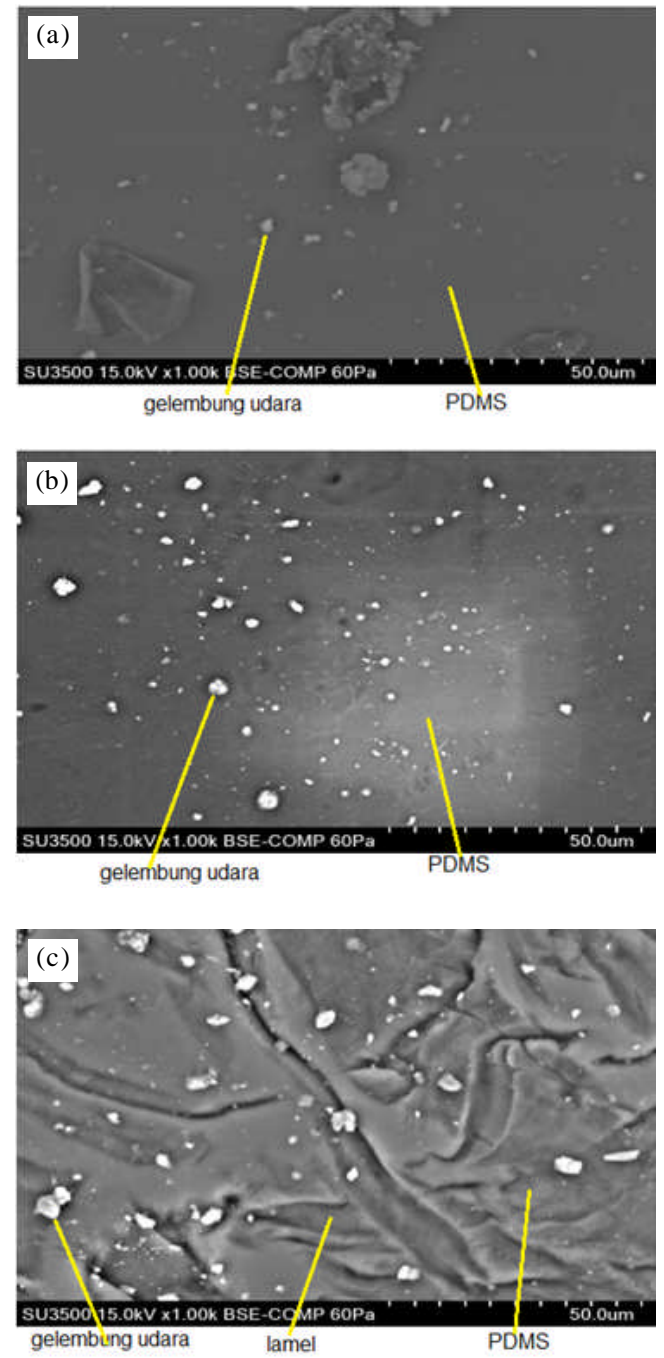

Gambar 2. Hasil analisis SEM dengan suhu $70{ }^{\circ} \mathrm{C}$ variasi (a). 0,032 mL, (b). 0,048 mL, dan (c). 0,064 mL

Hasil SEM variasi jumlah tetesan pada suhucuring $80{ }^{\circ} \mathrm{C}$ dengan variasi jumlah tetesan $0,032 \mathrm{~mL}, 0,048 \mathrm{~mL}$, dan $0,064 \mathrm{~mL}$ dapat dilihat dalam Gambar 4. Pada jumlah tetesan 0,032 mL terlihat masih banyak terdapat lamel gelembung udara yang mulai menyatu.
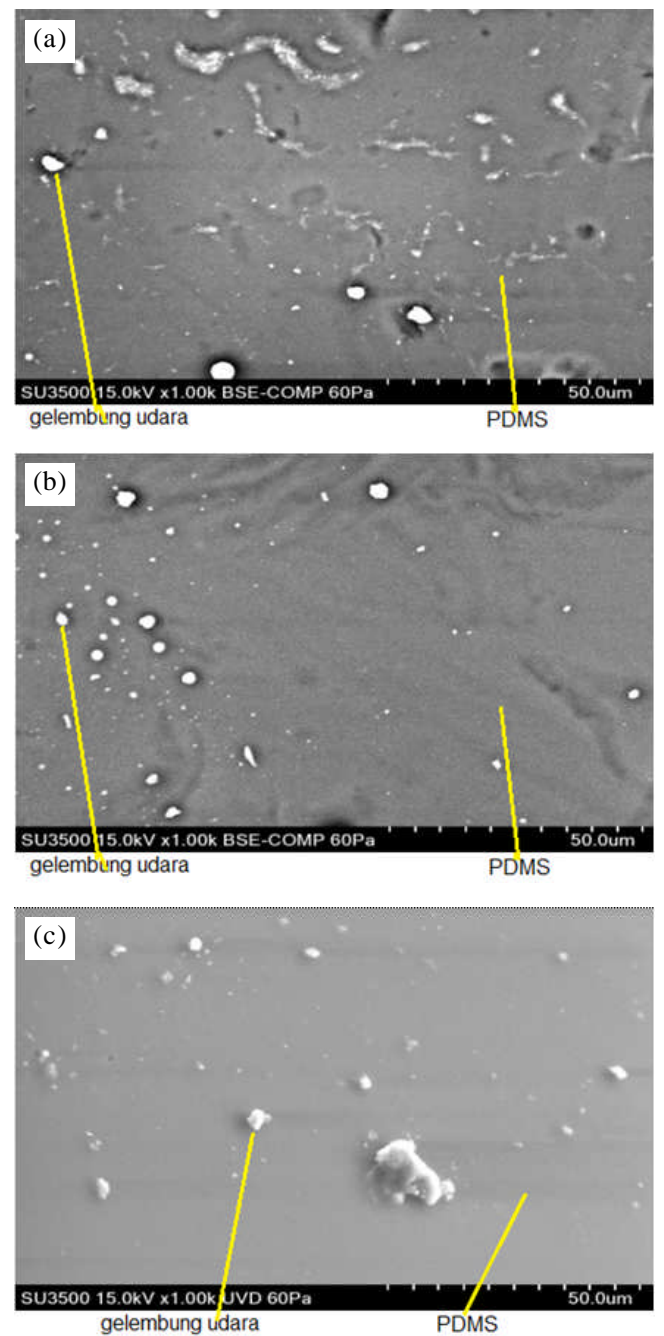

Gambar 4. Hasil analisis SEM-EDS dengan suhu $80{ }^{\circ} \mathrm{C}$ variasi (a) 0,032 mL, (b) 0,048 mL, dan (c) 0,064 mL.

Lensa dengan jumlah tetesan $0,048 \mathrm{~mL}$ mulai terdapat lamel dari hasil penggabungan udara pada lensa yang sudah mulai keluar dan jumlah gelembung yang terperangkap lebih sedikit daripada jumlah tetesan $0,032 \mathrm{~mL}$. Pada jumlah tetesan $0,064 \mathrm{~mL}$ hanya terdapat sedikit gelembung udara.

Gambar 5 menunjukkan hasil SEM yang memiliki variasi jumlah tetesan pada suhucuring $90^{\circ} \mathrm{C}$. Pada Gambar 5 terlihat adanya gelembung udara yang besar pada sampel (a), sedangkan pada sampel (b) terdapat banyak gelembung udara yang berukuran kecil pada hasil lensa invers.Lensa pada jumlah tetesan $0,064 \mathrm{~mL}$ terdapat gelembung udara yang sedikit karena gelembung udara yang bergabung mulai hilang sehingga membentuk lamel.

Proses curing mempengaruhi morfologi lensa hal ini disebabkan oleh proses curing dimana material mengalami proses crosslink secara sempurna.Ketika suhu proses curingdiberikan rendah maka tidak semua sistem antara matriks dengan hardener mengalami crosslinking dan masih terdapat rantai matriks dan hardener atau curingagent yang bergerak bebas [10]. 

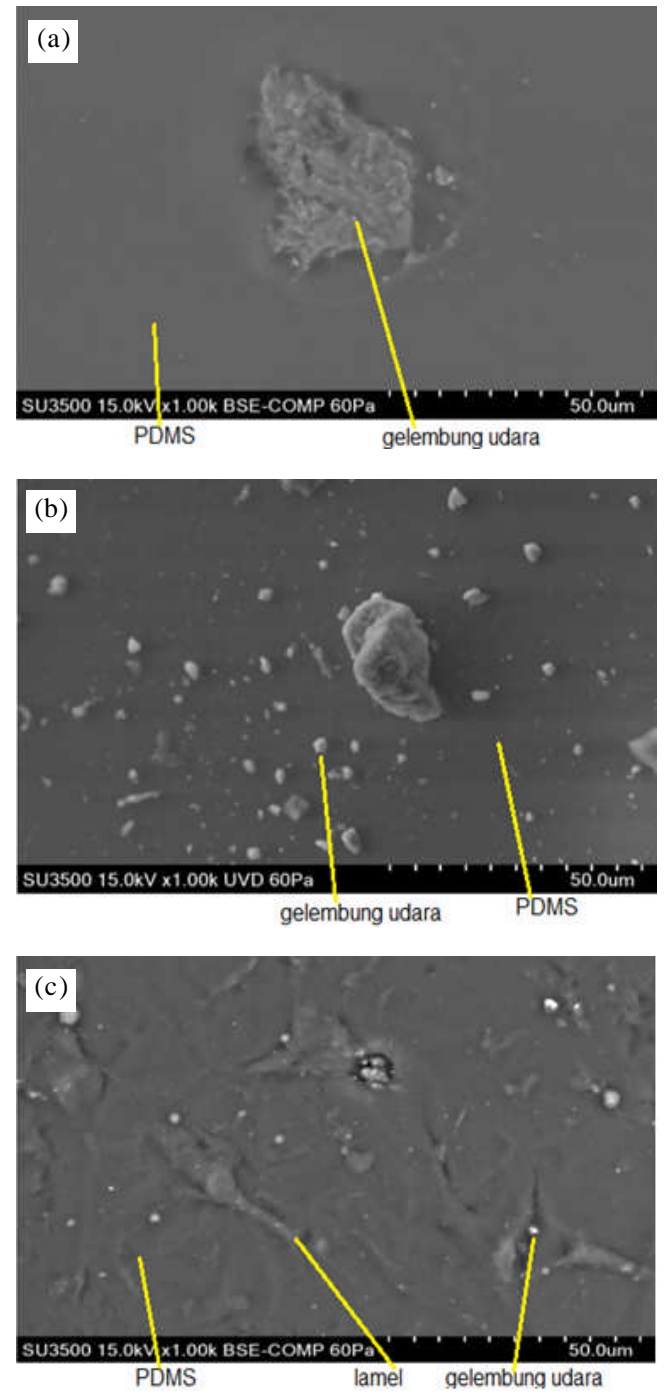

Gambar 5. Hasil analisis SEM dengan suhu $90{ }^{\circ} \mathrm{C}$ variasi (a). 0,032 mL, (b). 0,048 mL dan (c). 0,064 mL.

Sehingga udara yang terperangkap masih dapat bergerak keluar dan tidak membentuk gelembung di dalam lensa.

Hasil SEM menunjukkan bahwa semakin banyak jumlah tetesan maka semakin sedikit gelembung yang terperangkap sedangkan semakin tinggi suhu maka semakin banyak gelembung yang terdapat pada lensa.Hal ini disebabkan semakin banyak jumlah tetesan maka semakin banyak volume PDMS sehingga waktu proses untuk terjadi crosslinking semakin lama. Lamanya waktu tersebutmenyebabkan gelembung yang terperangkap dapat hilang secara perlahan. Sebelum menghilang gelembung akan membentuk lamel dan kemudian menghilang. Hasil SEM lensa invers pada variasi suhu $90{ }^{\circ} \mathrm{C}$ dengan jumlah tetesan $0,032 \mathrm{~mL}$, memperlihatkan hanya terdapat satu gelembung lensa invers dengan variasi suhu $90^{\circ} \mathrm{C}$ dengan jumlah tetesan $0,032 \mathrm{~mL}$ lebih baik sebab pada saat proses penetesan udara yang terdapat pada jarum suntik lebih sedikit. Jumlah udara yang lebih sedikit mempengaruhi hasil tetesan sehingga pada lensa dengan variasi $90{ }^{\circ} \mathrm{C}$ dengan jumlah tetesan $0,032 \mathrm{~mL}$ hanya terdapat satu gelembung lebih sedikit dibandingkan lensa dengan variasi yang lain. Oleh karena itu, untuk memilih lensa invers yang baik perlu dilihat dari karakterisasi termal lensa karena sifat termal mempengaruhi hasil gambar yang dihasilkan oleh lensa invers. Karakterisasi yang digunakan dengan menggunakan TGA untuk mengetahui kualitas lensa karena lensa invers akan mengalami penurunan kualitas berupa degradasi.

\section{Analisis TGA}

Pada penelitian ini dilakukan variasi dengan salah satunya yaitu suhu. Suhu berpengaruh pada sifat polimer agar tidak terjadi degradasi. Degradasi pada polimer disebabkan karena adanya penurunan sifat dari polimer yang salah satunya disebabkan oleh suhu [14]. Agar pemakaian lensa dapat digunakan dengan hasil yang baik diperlukan suhu degradasi (Td). Td akan mempengaruhi sifat lensa apabila lensa telah terdegradasi maka akan terlihat menguning sehingga gambar yang dihasilkan lensa akan menghasilkan gambar yang kurang akurat. Dari hasil analisis TGA pada variasi suhu $70^{\circ} \mathrm{C}$, $80{ }^{\circ} \mathrm{C}$, dan $90^{\circ} \mathrm{C}$ pada jumlah tetesan $0,032 \mathrm{~mL}$ kemudian diolah dengan menggunakan software Origin Pro 9.1 diperoleh pada Gambar 6, Gambar 7 dan Gambar 8.

Pada hasil analisis TGA didapatkan hasil pada suhu pemanasan $70{ }^{\circ} \mathrm{C}$ nilai $\mathrm{Td}$ sebesar $301,5^{\circ} \mathrm{C}$, pada suhu pemanasan $80{ }^{\circ} \mathrm{C}$ nilai $\mathrm{Td}$ sebesar $302^{\circ} \mathrm{C}$ dan pada

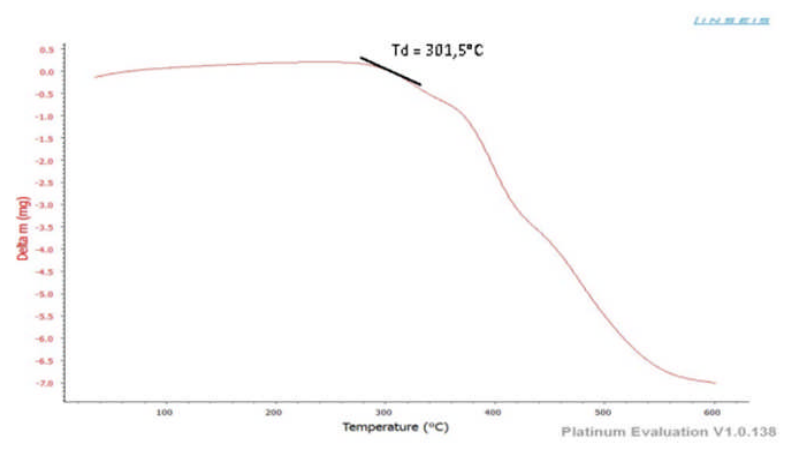

Gambar 6. Hasil analisis $T G A$ Suhu $70{ }^{\circ} \mathrm{C}$.

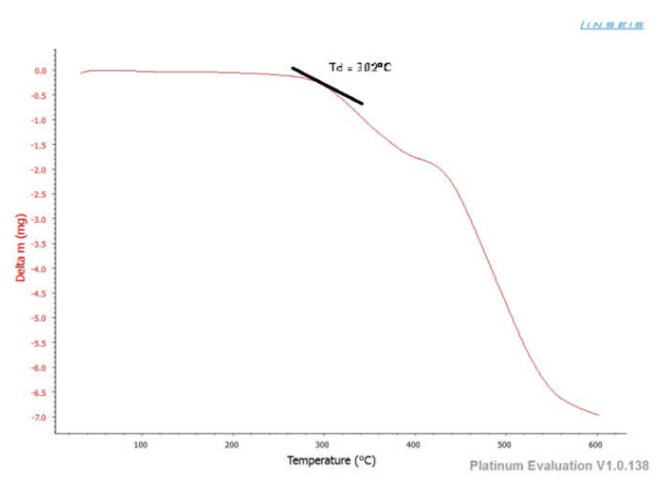

Gambar 7. Hasil analisis $T G A$ Suhu $80{ }^{\circ} \mathrm{C}$ 


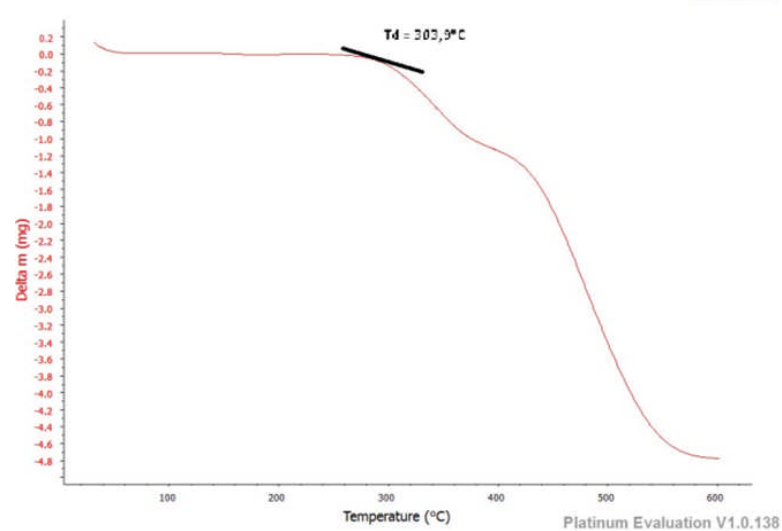

Gambar 8. Hasil analisis TGA Suhu $90{ }^{\circ} \mathrm{C}$.

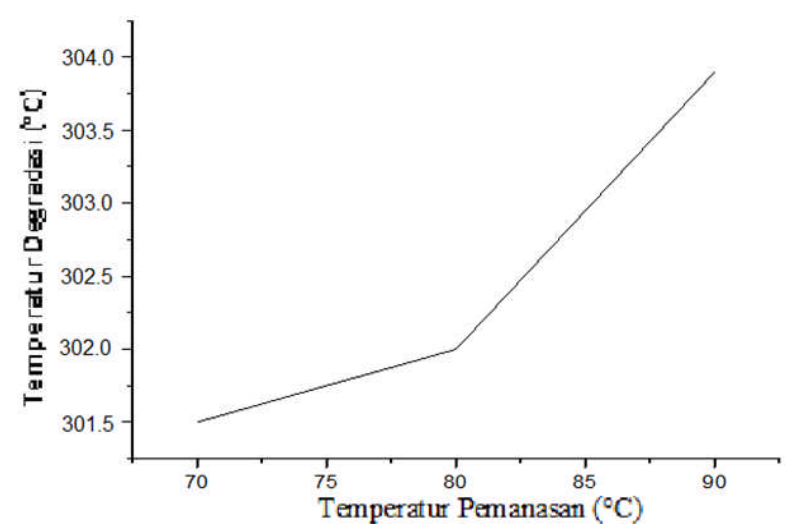

Gambar 9. Grafik nilai Td.

suhu pemanasan $90{ }^{\circ} \mathrm{C}$ nilai $\mathrm{Td}$ sebesar $303,9{ }^{\circ} \mathrm{C}$. Dari hasil tersebut terlihat pada variasi suhu curing $70{ }^{\circ} \mathrm{C}$ hingga $90{ }^{\circ} \mathrm{C}$ maka nilai Td dari lensa invers tersebut tidak berpengaruh begitu signifikan.

Kenaikan nilai $\mathrm{Td}$ berbanding lurus dengan kenaikan suhu pemanasan. Hal ini disebabkan pada saat terjadi proses curing pada suhu semakin tinggi maka tidak terdapat gas yang menghalangi terjadinya pembentukan rantai atau cross linking antara base PDMS dengan curing agent PDMS. Oleh karena itu, ikatan rantai akan semakin cepat terbentuk sehingga untuk mendegradasi sampel diperlukan suhu yang lebih tinggi dibandingkan suhu yang lebih rendah. Terlihat adanya kenaikan seiring dengan suhu proses curing yang dilakukan pada sampel tersebut. Suhu degradasi ini berhubungan erat dengan stabilitas termal, stabilitas termal diukur berdasarkan reaksi dekomposisi. Stabilitas termal berhubungan erat dengan ikatan energi antara atom-atom dalam polimer, ikatan energi yang tinggi akan menghasilkan stabilitas termal yang lebih tinggi [11].

\section{KESIMPULAN}

Polydimethylsiloxane dapat digunakan sebagai lensa invers karena memiliki sifat optik dan termalyang baik. Semakin tinggi suhupada pembuatan lensa invers maka nilai intensitas lensa semakin kecil, sedangkan semakin rendah suhunya maka nilai intensitas lensa semakin tinggi. Pengaruh volume tetesan menunjukkan semakin banyak maka semakin besar nilai intesitas lensa. Hasil nilai intensitas cahaya terbesar pada lensa invers dengan variasi suhu $70^{\circ} \mathrm{C}$ dengan jumlah tetesan 4 tetes $(0,064 \mathrm{~mL})$ yaitu sebesar 177 lux. Morfologi lensa dipengaruhi oleh suhu dan volume tetesan, semakin tinggi suhu maka semakin banyak gelembung udara yang terperangkap. Pengaruh volume tetesan semakin banyak volume tetesan maka semakin sedikit gelembung yang terperangkap sebaliknya semakin sedikit volume tetesan maka semakin banyak gelembung udara. Hasil analisis $T G A$ ini menunjukkan variasi suhu curing pada lensa invers tidak banyak berpengaruh terhadap nilai $\mathrm{Td}$. Lensa invers dengan variasi suhu $90{ }^{\circ} \mathrm{C}$ memiliki nilai Td paling tinggi yaitu sebesar $303,9^{\circ} \mathrm{C}$.Dari hasil karakterisasi nilai intensitas dan analisis $S E M$ didapatkan lensa invers yang baik digunakan adalah lensa dengan variasi suhu $70{ }^{\circ} \mathrm{C}$ dengan jumlah tetesan 4tetes.

\section{UCAPAN TERIMAKASIH}

Penulis mengucapkan terima kasih untuk Lembaga Ilmu Pengetahuan Indonesia program Unggulan untuk suport dananya. Penulis juga mengucapkan terimakasih kepada Tri Partutidan Adhitya Trenggono untuk diskusi dan masukannya.

\section{DAFTAR ACUAN}

[1]. Rohmadi.Teknologi Polimer. Yogyakarta: Universitas Gajah Mada, 2010.

[2]. Z. Wang. "Polydimethylsiloxane Mechanical Properties Measured by Macroscopic Compression and Nanoindentation Techniques". Scholar Commons, Graduate Thesis and Dissertations, University of South Florida, 2011

[3]. W. M. Lee, A. Upadhya, P.J. Reece, and Tri Glang Phan. "Fabricating Low Cost and High Performance Elastomer Lenses Using Hanging Droplets.” Biomedical Optics Express, vol. 5, pp. 1626-1635, 2014.

[4]. Adrian Bele, George Stiubianu, Cristian-Dragos Varganici, Mircea Ignat, and Maria Cazacu. "Silicone Dielectric Elastomers Based on Radical Crosslinked High Molecular Weight Polydimethylsiloxane CoFilled with Silica and Barium Titanate." Journal of Materials Science, vol. 50, pp. 6822-6832, October 2015.

[5]. N. E. Stankova, P. A. Atanasov, Ru. G. Nikov, R. G. Nikov, N. N. Nedyalkov, T. R. Stoyanchov, N. Fukata, K. N. Kolev, E. I. Valova, J. S. Georgieva, and St. A. Armyanov. "Optical Properties of Polydimethylsiloxane (PDMS) During Nanosecond Laser Processing.” Applied Surface Science, vol. 374, pp. 96-103, June2016. 
[6]. Gang Li and Shengyong Xu. "Small Diameter Microchannel of PDMS and Complex ThreeDimensional Microchannel Network." Materials and Design, vol. 81, pp. 82-86, 2015.

[7]. H.S. Hong, L.X. Chen, Q.W. Zhang, and F. He. “The Structure and Pervaporation Properties for Acetic Acid/Water of Polydimethylsiloxane Composite Membranes." J. Mater. Des., vol. 34, pp. 732-738, 2012.

[8]. E.K. Her, T.J. Ko, B. Shin, H. Roh, W. Dai, W.K. Seong, H.Y. Kim, K.R. Lee, K.H. Oh, and M.W. Moon. "Superhydrophobic Transparent Surface of Nanostruc-Tured Poly(Methyl Methacrylate) Enhanced by A Hydrolysis Reaction.” Plasma Processes Polym, vol. 10, pp. 481-488, 2013.

[9]. Z. Hua, J. Yang, T. Wang, G. Liu, and G. Zhang. "Transparent Surface with Reversiblyswitchable Wettability Between Superhydrophobicity and Superhydrophilicity." Langmuir, vol. 29, pp. 1030710312, 2013.
[10]. Amit Bhattacharya, James W. Rawlins, and Paramita Ray. "Polymer Grafting and Crosslinking." New York: John Wiley \& Sons, Inc., 2009.

[11]. William D. Callister, Jr. and David G. Rethwisch. "Materials Science and Engineering an Introduction". $9^{\text {th }}$ edition. New York: John Wiley \& Sons, Inc., 2013.

[12]. Ganijanti A. S. "Gelombang dan Optika. Jakarta:Salemba Teknika, 2011.

[13]. Abdullah, R .Asas-asas Ilmu Alam Universitas. Ujung Pandang: Lembaga Penerbitan Universitas Hasanuddin, 1985.

[14]. P.M. Visakh, and Yoshihiko, A. Thermal Degradation of Polymer Blends, Composites and Nanocomposites. Switzerland: Springer International Publishing, 2015. 